This item was submitted to Loughborough's Research Repository by the author.

Items in Figshare are protected by copyright, with all rights reserved, unless otherwise indicated.

\title{
Synchrotron X-ray and neutron investigation of the structure and thermal expansion of the monoclinic Al13Cr2 phase
}

\section{PLEASE CITE THE PUBLISHED VERSION}

https://doi.org/10.1016/j.jallcom.2018.12.132

\section{PUBLISHER}

(C) Elsevier

\section{VERSION}

AM (Accepted Manuscript)

\section{PUBLISHER STATEMENT}

This paper was accepted for publication in the journal Journal of Alloys and Compounds and the definitive published version is available at https://doi.org/10.1016/j.jallcom.2018.12.132

\section{LICENCE}

CC BY-NC-ND 4.0

\section{REPOSITORY RECORD}

Liotti, Enzo, Caroline Kirk, I. Todd, K.S. Knight, and Simon Hogg. 2019. "Synchrotron X-ray and Neutron Investigation of the Structure and Thermal Expansion of the Monoclinic Al13cr2 Phase". figshare. https://hdl.handle.net/2134/36512. 


\title{
Synchrotron X-ray and neutron investigation of the structure and thermal expansion of the monoclinic \\ $\mathrm{Al}_{13} \mathrm{Cr}_{2}$ phase
}

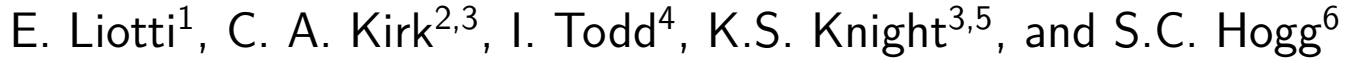 \\ ${ }^{1}$ Department of Materials, University of Oxford, Parks Road, Oxford, OX1 3PH, UK \\ ${ }^{2}$ School of Chemistry, University of Edinburgh, Edinburgh, EH9 3FJ, UK \\ ${ }^{3}$ Department of Earth Sciences, The Natural History Museum, Cromwell Road, London, \\ SW7 5BD, UK \\ ${ }^{4}$ Department of Materials Science and Engineering, Sheffield University, Mappin Street, \\ Sheffield, S1 3JD, UK \\ ${ }^{5}$ Department of Earth Sciences, University College London, Gower Street, London, WC1E \\ 6BT, UK \\ ${ }^{6}$ Department of Materials, Loughborough University, Loughborough LE11 3TU, UK
}

\begin{abstract}
The crystal structure of the $\mathrm{Al}_{13} \mathrm{Cr}_{2}$ intermetallic phase at $298 \mathrm{~K}$ was studied by synchrotron X-ray and neutron diffraction through the analysis of data collected on bulk samples, one in the as-cast condition, one after annealing at $773 \mathrm{~K}$ for $24 \mathrm{~h}$ and one for $168 \mathrm{~h}$. Furthermore the thermal expansion behaviour of the structure was investigated for the first time in-situ up to $773 \mathrm{~K}$. The diffraction patterns were analysed using whole pattern fitting techniques using the Le Bail and Pawley methods as well as the Rietveld method. The structure was found to be monoclinic with space group $C 2 / m$ and lattice parameters $a=25.3101 \AA, b$ $=7.6081 \AA, c=10.9689 \AA$ and $\beta=128.704^{\circ}$ at $298 \mathrm{~K}$ in the as-cast condition.
\end{abstract}


From the temperature variation of the unit cell parameters the principal axes of the thermal expansion tensor were calculated. The largest principal axis has a magnitude of $1.66 \times 10^{-5} \mathrm{~K}^{-1}$ and lies parallel to $\boldsymbol{b}$, the second largest lies in the $\boldsymbol{a}-\boldsymbol{c}$ plane at an angle of $\sim 37^{\circ}$ from $\boldsymbol{c}$ in the direction of $-\boldsymbol{a}$ with a value $1.64 \times 10^{-5} \mathrm{~K}^{-1}$ whereas the smallest lies at $\sim 53^{\circ}$ to $\boldsymbol{c}$ in the direction of $+\boldsymbol{a}$ and has a value of $1.31 \times 10^{-5} \mathrm{~K}^{-1}$. Analysis of the behaviour of the icosahedra revealed that their expansion is highly anisotropic and the level of anisotropy is related to the point symmetry of the central $\mathrm{Cr}$ atoms. 


\section{Introduction}

The $\mathrm{Al}_{13} \mathrm{Cr}_{2}$ phase, also called $\mathrm{Al}_{45} \mathrm{Cr}_{7}$ or $\mathrm{Al}_{7} \mathrm{Cr}$ depending on the exact stoichiometry, is an intermetallic with a complex, low symmetry crystal structure, also reported as an icosahedral quasicrystal (iQC) approximant ${ }^{1}$. The phase forms in a number of $\mathrm{Cr}$ containing aluminium alloys including ternary $\mathrm{Al}-\mathrm{Cr}-\mathrm{Cu}$ and $\mathrm{Al}-\mathrm{Cr}-\mathrm{Zr}$ alloys ${ }^{2-4}$ and quaternary $\mathrm{Al}-\mathrm{Fe}-\mathrm{Cr}-\mathrm{X}(\mathrm{X}: \mathrm{Ti}, \mathrm{V}, \mathrm{Nb}, \mathrm{Mn}, \mathrm{Ta}, \mathrm{Si})^{5-9}$. The latter group belong to a new family of alloys that are able to form large fractions of nanoscale, hard and thermally stable dispersoids which gives the material high-elevated temperature strength capable of competing with commercial titanium alloys $\frac{10}{10}$. Despite the numerous studies on the mechanical properties and thermal stability of these alloys, limited information is available about the lattice parameters and crystal structure of the main constituent intermetallics preventing the development of reliable mechanical models. In the work presented here, the crystal structure of $\mathrm{Al}_{13} \mathrm{Cr}_{2}$ within a rapidly solidified bulk sample has been investigated using synchrotron X-ray and neutron powder diffraction data collected on samples in the as-cast condition and after annealing the material at $773 \mathrm{~K}$ for $24 \mathrm{~h}$ (one day) and $168 \mathrm{~h}$ (one week). Unit cell parameters were calculated and compared with the literature values and the thermal expansion of the unit cell, measured up to a temperature of $773 \mathrm{~K}$, was also calculated. Atomic positions were refined for the annealed samples and used to study the structural thermal behaviour of the icosahedra around the $\mathrm{Cr}$ atoms. The newly presented thermal expansion data will contribute towards the improvement of stresses and strains predictions in metallurgical processes and working components behaviour of $\mathrm{Al}_{13} \mathrm{Cr}_{2}$ containing alloys.

\subsection{Crystal structure}

In the binary $\mathrm{Al}-\mathrm{Cr}$ system ${ }^{11}$, the $\mathrm{Al}_{13} \mathrm{Cr}_{2}$ phase is one of the intermetallic compounds populating the Al-rich end phase diagram and exists over the compositional range $\sim 21$ $24 \mathrm{wt} \% \mathrm{Cr}(12-14 \mathrm{at} \%)^{11-15}$. It can form directly from the liquid both by eutectic or peritectic reactions ${ }^{11}$. The crystal structure of $\mathrm{Al}_{13} \mathrm{Cr}_{2}$ was studied by Cooper ${ }^{16}$ using X-ray diffraction techniques on single crystals extracted from a bulk sample with nominal 


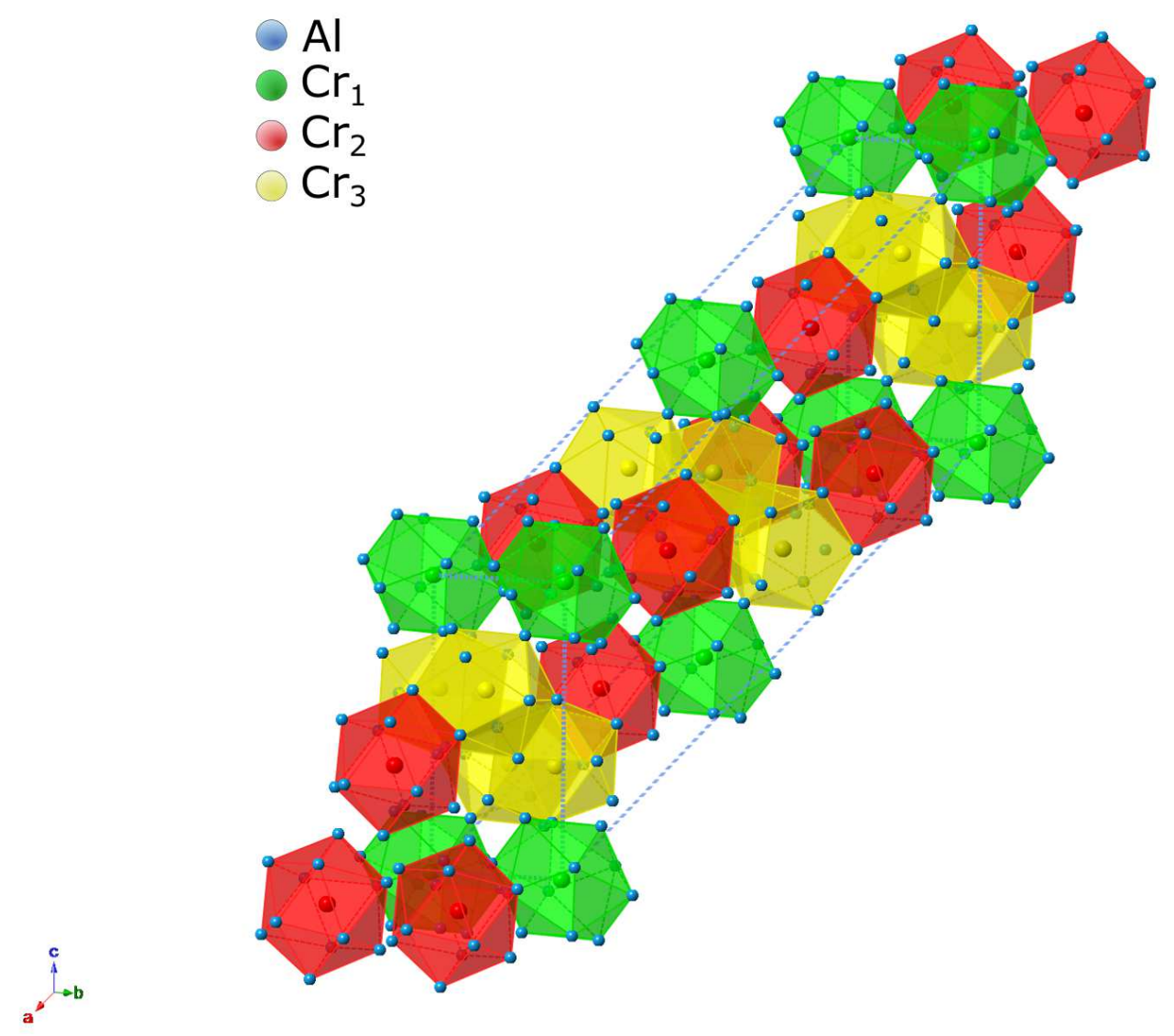

Figure 1: The monoclinic crystal structure of $\mathrm{Al}_{13} \mathrm{Cr}_{2}\left({ }^{16}\right)$, space group $C 2 / m, a=25.196 \AA, b=$ $7.574 \AA c=10.949 \AA$ and $\beta=128.72^{\circ}$. The icosahedra around the $\mathrm{Cr}$ atoms are shown.

composition of $\mathrm{Al}_{99} \mathrm{Cr}_{1} \mathrm{wt} \%$. The phase was reported to crystallise in the monoclinic space group $C 2 / m$ with the lattice parameters $a=25.196 \AA, b=7.574 \AA, c=10.949 \AA$ and $\beta=128.72^{\circ}$. Very similar lattice parameters were obtained by Ohnishi ${ }^{17}$ from an X-ray powder diffraction study of particles extracted from an $\mathrm{Al}_{97} \mathrm{Cr}_{3}$ wt $\%$ alloy, although the $a$ parameter was found to be slightly larger $(a=25.256 \AA, b=7.582 \AA c=10.955 \AA$ and $\left.\beta=128.7^{\circ}\right)$.

The crystal structure is shown in Fig. 1, the unit cell contains 104 atoms, 14 of which are $\mathrm{Cr}$. All the $\mathrm{Cr}$ atoms are co-ordinated by 12 other atoms ( $\mathrm{Al}$ and $\mathrm{Cr}$ ) and located at the centers of nearly regular or slightly distorted icosahedra whereas the $\mathrm{Al}$ atoms are at their vertices (see Fig. 2). We will refer to the icosahedra around $\mathrm{Cr}_{1}, \mathrm{Cr}_{2}$ and $\mathrm{Cr}_{3}$ as $i \mathrm{CO}_{1}, i \mathrm{CO}_{2}$ and $i \mathrm{CO}_{3}$. These icosahedra are either sharing a vertex, an edge, a triangular face or interlocked and a comprehensive description of their interconnections is given in 18,19 . The number of independent bond lengths of the icosahedra reflects the 

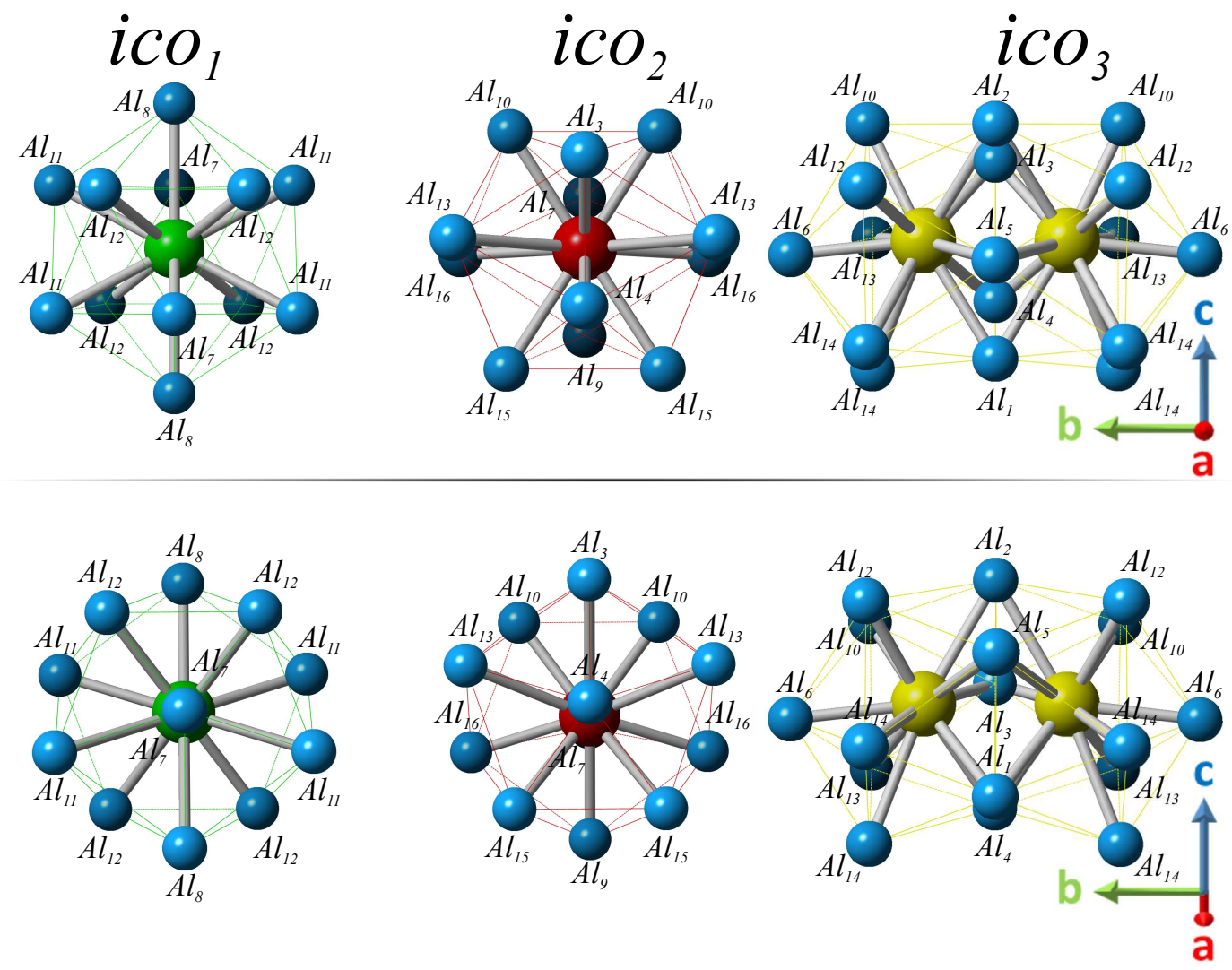

Figure 2: Icosahedra formed around the three $\mathrm{Cr}$ atoms $\left(\mathrm{Cr}_{1}\right.$ is green, $\mathrm{Cr}_{2}$ is red and $\mathrm{Cr}_{3}$ is yellow, $\mathrm{Al}$ atoms in blue). For $\mathrm{Cr}_{3}$ two adjacent icosahedra, which form a decagon, are represented. The top row shows the polyhedra looking down the $\boldsymbol{a}$ axis, while in the bottom row the view is rotated $30^{\circ}$ around the $\boldsymbol{b}$ axis towards $-\boldsymbol{c}$. The Wyckoff positions of the atoms are: $\mathrm{Cr}_{1}$ on site $2 a, \mathrm{Cr}_{2}$ on site $4 i, \mathrm{Cr}_{3}$ on $8 j, \mathrm{Al}_{1}$ on $2 d, \mathrm{Al}_{2-9}$ on $4 i$ and $\mathrm{Al}_{10-16}$ on $8 j$.

point group symmetry of the $\mathrm{Cr}$ Wyckoff site: $i \mathrm{CO}_{1}$ is the most regularly co-ordinated with $i \mathrm{CO}_{3}$ being the most irregular. ico $\mathrm{C}_{1}$, which contains two $\mathrm{Al}_{7}$ and $\mathrm{Al}_{8}$ and four $\mathrm{Al}_{11}$ and $\mathrm{Al}_{12}$, has point group symmetry $2 / \mathrm{m}$ with a mirror plane passing through the $\mathrm{Al}_{7}$ and $\mathrm{Al}_{8}$ atoms and a two-fold rotation axes perpendicular to it. The vertex interatomic distances from the central atom have values over the range $2.567 \AA$ to $2.922 \AA$. $i \mathrm{co}_{2}$, with point group symmetry $m$, includes one each of $\mathrm{Al}_{3}, \mathrm{Al}_{4}, \mathrm{Al}_{7}$ and $\mathrm{Al}_{9}$, lying on the mirror planes and two $\mathrm{Al}_{10}, \mathrm{Al}_{13}, \mathrm{Al}_{15}$ and $\mathrm{Al}_{16}$ outside of it. The vertex distances range from $2.483 \AA$ to $2.911 \AA$. In $i \mathrm{CO}_{3}$, which has general point group symmetry, the vertices are $\mathrm{Al}_{1}, \mathrm{Al}_{2}, \mathrm{Al}_{3}, \mathrm{Al}_{4}, \mathrm{Al}_{5}, \mathrm{Al}_{6}, \mathrm{Al}_{10}, \mathrm{Al}_{12}, \mathrm{Al}_{13}, \mathrm{Al}_{14_{1}}, \mathrm{Al}_{14_{2}}$ and $\mathrm{Cr}_{3}$ and all the distances are different spreading from $2.468 \AA$ to $2.796 \AA$. The two interlocked icosahedra sharing the $\mathrm{Cr}_{3}$ atom appear as a decagon when they are projected along the $a$ axis (see Fig. 2) 1 .

The structure can also be alternatively described in term of close packed layered structure 
if the icosahedra are used as the lattice points (more details are given section S.1 of the Supplementary Materials).

\section{Experimental procedure}

\subsection{Material}

A sample with nominal composition $\mathrm{Al}_{77} \mathrm{Cr}_{23}$ wt\% $\left(\mathrm{Al}_{87} \mathrm{Cr}_{13}\right.$ at $\left.\%\right)$ was produced by arcmelting from pure elements ( $\mathrm{Al}$ : 99,99wt\%, $\mathrm{Cr}$ : 99,9wt\%) under an $\mathrm{Ar}$ atmosphere and directly cast into a $5 \mathrm{~mm}$ diameter cylindrical rod using a suction casting facility attached to the arc melting furnace. The rod was subsequently cut into three parts and two of them sealed under a vacuum in a silica tube and annealed for 24 hours (one day) and 168 hours (one week) at $773 \mathrm{~K}$. The annealing was carried out to remove residual stresses caused by rapid cooling and dissolve any metastable phase formed during solidification.

\subsection{EPMA}

Backscattered-Electron (BSE) imaging and Electron Probe Micro Analysis (EPMA) were performed using a JEOL JXA-8800R microprobe operating with two wavelengthdispersive (WD) spectrometers set at $40^{\circ}$ angle (TAP crystal for Al and PETJ for $\mathrm{Cr}$ ), an accelerating voltage of $15 \mathrm{kV}$ and beam current of $3.055 \times 10^{-8} \mathrm{~A}$. Within each phase quantitative analysis were acquired over large areas (tens of $\mu \mathrm{m}^{2}$ ). Point analysis (performed in spot mode) were also collected with a minimum of three points per phase. Pure $\mathrm{Al}$ and pure $\mathrm{Cr}$ were used as primary standards and the peak intensities corrected using the ZAF method. 


\subsection{Neutron and X-ray diffraction}

Both neutron and X-ray synchrotron data were collected to identify the phases present in the different samples, measure their lattice parameters and determine the crystal structure of the $\mathrm{Al}_{13} \mathrm{Cr}_{2}$ phase at room temperature and up to $773 \mathrm{~K}$. Also the lattice microstrains were calculated from peak broadening in order to evaluate the effect of annealing on residual stresses.

Samples in the as-cast and annealed for one day conditions were studied using neutron diffraction while high temperature synchrotron X-ray experiments were carried out on the material annealed for one week, which was assumed to be the one with the lowest level of residual stresses, for an accurate measurement of the lattice and structural parameters.

Powder Neutron diffraction (PND) patterns of the as-cast and annealed for one day samples were collected on the high-resolution powder diffractometer HRPD at the ISIS spallation source over the time-of-flight range 30-130 ms. The bulk samples were contained in thin-walled $11 \mathrm{~mm}$ diameter vanadium cans that were mounted in the beam. Data were collected at room temperature approximately 60 min duration for the as-cast and $480 \mathrm{~min}$ for the annealed samples.

Synchrotron X-ray powder diffraction (XRD) experiments were carried out on the High Resolution Powder Diffraction beamline I11 at the Diamond Light Source (UK). The bulk alloy, which had been annealed for one week, was ground into a fine powder and inserted into a $0.5 \mathrm{~mm}$ Lindemann capilliary before being mounted on the $\mathrm{I} 11$ diffractometer. The capillary was magnetically attached to the spinning sample holder, which rotates the sample to randomise the particles and minimise any preferred orientation effects, and measured in Debye-Scherrer (transmission) geometry. The data were collected over the range $5^{\circ}$ to $140^{\circ} 2 \theta$ for 30 minutes. The X-ray wavelength $(0.826262 \AA)$ and $2 \theta$ zero offset were calibrated by refinement of the diffraction pattern of a Si standard (NIST SRM640c). The diffractometer was setup using the 5 Multi-Analyser Crystal detectors (MACs) each having 9 Si111 crystals with a $2 \theta$ resolution of $\sim 0.005^{\circ}$ at $10 \mathrm{keV}^{20}$. High temperature experiments from room temperature to $773 \mathrm{~K}$ were carried out on a ground powder sample of the annealed material using a hot air blower positioned close to the 


\begin{tabular}{|c|c|c|c|}
\hline Sample & Condition & Instrument & Data collection parameters \\
\hline As-cast & $298^{\circ} \mathrm{C}$ & Neutron & TOF range $=30-130 \mathrm{~ms}$ \\
\hline Annealed one day & $298^{\circ} \mathrm{C}$ & Neutron & TOF range $=30-130 \mathrm{~ms}$ \\
\hline Annealed one week & $298^{\circ} \mathrm{C}$ to $773^{\circ} \mathrm{C}$ & Synchrotron X-ray & $\begin{array}{l}2 \theta \text { range: } 5^{\circ} \text { to } 140^{\circ} 0.005^{\circ} \text { step, } 1 \mathrm{~h} \\
\text { at room } \mathrm{T}, 30 \mathrm{~min} \text { for } \mathrm{T}>25^{\circ} \mathrm{C} \text {, wave- } \\
\text { length: } 0.826262 \AA\end{array}$ \\
\hline
\end{tabular}

Table 1: Experiment summary and data collection information.

capillary. Six patterns were recorded at $298 \mathrm{~K}, 373 \mathrm{~K}, 473 \mathrm{~K}, 573 \mathrm{~K}, 673 \mathrm{~K}$ and $773 \mathrm{~K}$. A summary list of the experiments with details about the data collection parameters is reported in table 1

\subsection{Refinement of the neutron data}

PND patterns were refined using the General Structure Analysis Software (GSAS) 2122 . Only data collected using the backscattered detector, which has the highest $d$-space resolution, were used for the analysis. Electron microscopy revealed that the samples were multiphase and had a textured microstructure with grains generally elongated from the surface towards the centre. Therefore multiphase refinements were carried out using the LeBail method as the samples, which were in bulk form, could be affected by preferred orientations and the crystal structure of some of the impurity phases, which were present in small quantities, was not known. These refinements were preliminary to calculate the lattice parameters, the profile parameters and to measure size and strain. The background terms were refined first, followed by lattice parameters and finally profile parameters. The background of the TOF source was modelled with the 'Power series in $\mathrm{Q}^{* *} 2 \mathrm{n} / \mathrm{n}$ !' GSAS function \#4 with four terms, whereas the peak profile using GSAS TOF function number \#3 (convolution of back-to-back exponentials with pseudo-Voigt function). This peak shape function considers instrumental broadening Gaussian, while sample size and strain broadening are assumed to be Lorentzian allowing the sample contribution to be decoupled from the instrumental broadening. Thus only the Lorentzian component $\left(\gamma_{1}\right.$ and $\left.\gamma_{2}\right)$ of the profile function were refined while the other profile parameters were fixed to the values given in the instrument file from HRPD. From the values of the profile parameters isotropic strain broadening $e$ can be calculated using the 
relation:

$$
e=\frac{\gamma_{1}}{D I F C} 100 \%
$$

while size broadening $\beta_{s}$ from:

$$
\beta_{s}=\frac{D I F C K}{\gamma_{2}}
$$

where DIFC is a diffractometer constant and $\mathrm{K}$ is the Scherrer constant (set to 1 ).

\subsection{Refinement of the X-ray data}

XRD data of the sample annealed for one week were analysed using the software suite TOPAS academic (v4.1) 23 . A Pawley fit of the data was carried out initially to determine peak profile parameters and unit cell parameters, followed by a structural refinement using the Rietveld method. Data were modelled using a Chebychev background function with 15 parameters and a modified Thomson-Cox-Hasting pseudo Voigt profile function and fitted over the $2 \theta$ range $3.5^{\circ}$ and $60^{\circ}$. To obtain the physical contribution to the peak broadening, the instrumental contribution was determined by fixing the peak shape parameters to the values obtained from the refinement of a standard Si sample, mounted in a capillary. Peak broadening was assumed to be entirely caused by strain and calculated using the TOPAS built in macro as defined in ${ }^{24}$. This assumption was based on the observation made by electron microscopy which revealed the grains to have size in the range of tens of micrometers, assumed to be larger than any detectable contribution to the broadening. 

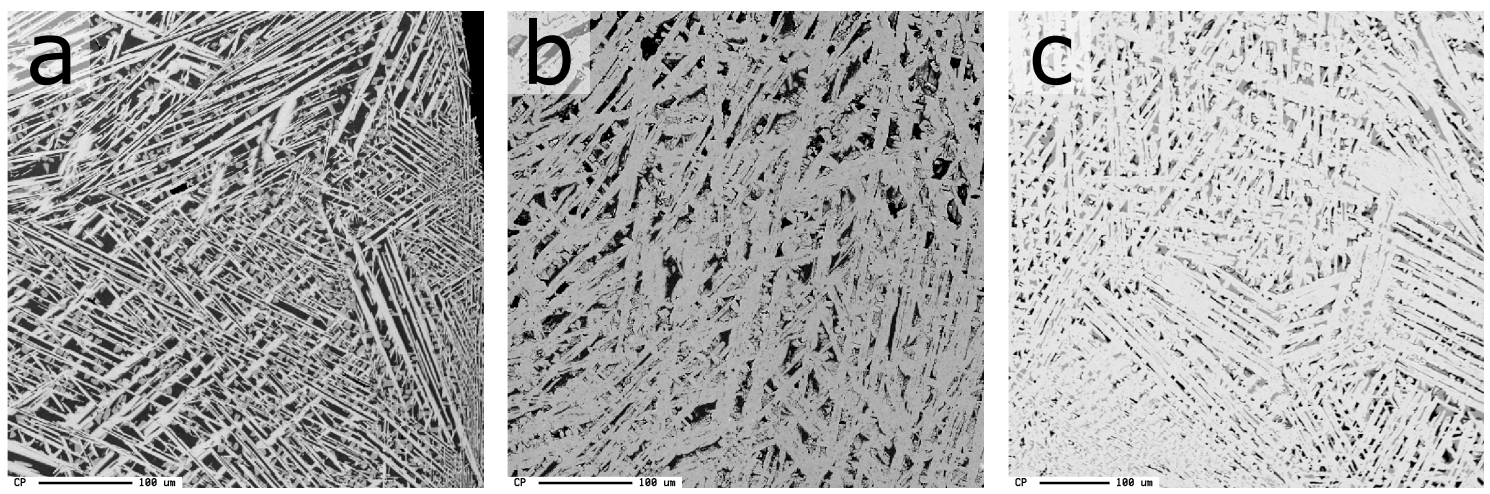

Figure 3: BSE image of the (a) as-cast, (b) annealed for one day and (c) annealed for one week microstructures.

\section{Results}

Electron microscopy and EPMA of the samples were carried out before refining the diffraction data in order to verify the homogeneity of the microstructure and the presence of extra phases formed during the casting process. The as-cast and annealed sample microstructures are shown in Fig. 3. The $\mathrm{Al}-\mathrm{Cr}$ intermetallics, visible as bright phases in the BSE images, formed elongated lamellae and plates with size ranging from a few tens of $\mu \mathrm{ms}$ up to $\mathrm{mm}$ scale. The micrographs also showed the presence of $\alpha$-Al within the interlamellar regions (darker areas). Annealing had the effect of coarsening the microstructure, however the overall morphology of the intermetallics did not change. The results of the compositional analyses are summarized in table 2. The as-cast sample contained three distinct phases with $\mathrm{Cr}$ contents of $2.3 \mathrm{wt} \%, 23.4 \pm 0.4 \mathrm{wt} \%$ and $31.7 \pm 0.9$ $\mathrm{wt} \%$ respectively. The first was the supersaturated $\alpha-\mathrm{Al}$ with a $\mathrm{Cr}$ content almost double the value reported in the literature. The second phase was the $\mathrm{Al}_{13} \mathrm{Cr}_{2}$, with a stoichiometry slightly in excess of $\mathrm{Cr}$ and closer to that of $\mathrm{Al}_{45} \mathrm{Cr}_{7}$. The third phase had a $\mathrm{Cr}$ content close to the stoichiometry of the phase $\mathrm{Al}_{4} \mathrm{Cr}$, although the value was within the compositional ranges of both $\mathrm{Al}_{4} \mathrm{Cr}$ and $\mathrm{Al}_{5} \mathrm{Cr} \frac{19}{}$. The annealed samples contained only two phases, $\alpha-\mathrm{Al}$ and $\mathrm{Al}_{13} \mathrm{Cr}_{2}$, as no detectable trace of the third metastable compound was found. The $\mathrm{Cr}$ content dissolved in the $\alpha-\mathrm{Al}$ was $1.6 \pm 0.5 \mathrm{wt} \%$ and $0.8 \pm 0.2 \mathrm{wt} \%$ in the annealed for one day and one week respectively. The $\mathrm{Al}_{13} \mathrm{Cr}_{2}$ composition did not vary, being $23.1 \pm 0.8 \mathrm{wt} \%$ in the annealed for one day material and $23.3 \pm 0.7 \mathrm{wt} \%$ in the annealed for one week. 


\begin{tabular}{llll}
\hline Phase & As-cast & Annealed one day & Annealed one week \\
\hline $\mathrm{Al}$ & 2.3 & $1.6 \pm 0.5$ & $0.8 \pm 0.2$ \\
$\mathrm{Al}_{13} \mathrm{Cr}_{2}$ & $23.3 \pm 0.4$ & $23.1 \pm 0.8$ & $23.3 \pm 0.7$ \\
$\mathrm{Al}_{4} \mathrm{Cr}$ & $31.7 \pm 0.9$ & - & - \\
\hline
\end{tabular}

Table 2: Cr content ( $w t \%)$ of the detected phases as measured from EPMA in the as-cast and annealed samples.

\subsection{As-cast material}

Due to the difficulties arising from uniquely identifying the third phase only on the basis of chemical information, multi-phase models were constructed to fit the data. Four models were tested using different mixtures of the four phases $\mathrm{Al}, \mathrm{Al}_{13} \mathrm{Cr}_{2}, \mathrm{Al}_{5} \mathrm{Cr}$ and $\mathrm{Al}_{4} \mathrm{Cr}$ with lattice parameters reported in table 3 . The best fit to the data was obtained with

\begin{tabular}{lllllll}
\hline \multirow{2}{*}{ Phase } & \multirow{2}{*}{ Space group } & \multicolumn{7}{c}{ Lattice parameters $(\AA)$} & \multirow{2}{*}{ Ref. } \\
& & \multicolumn{1}{c}{$(\AA)$} & \multicolumn{1}{c}{$c$} & $\beta$ & \\
\hline $\mathrm{Al}$ & $F m \overline{3} m$ & 4.049 & & & & {$[25$} \\
$\mathrm{Al}_{13} \mathrm{Cr}_{2}$ & $C 2 / m$ & 25.196 & 7.574 & 10.949 & 128.72 & {$[16]$} \\
$\mathrm{Al}_{4} \mathrm{Cr}$ & $P 2 / m$ & 8.716 & 23.946 & 16.386 & 119.33 & 17 \\
$\mathrm{Al}_{5} \mathrm{Cr}$ & $P 2$ & 12.880 & 7.652 & 10.639 & 122.20 & {$[17$} \\
\hline
\end{tabular}

Table 3: Space group and lattice parameters used as a starting point in the multi-phase refinement of the as-cast sample.

model 3 containing $\alpha$-Al, $\mathrm{Al}_{13} \mathrm{Cr}_{2}$ and $\mathrm{Al}_{4} \mathrm{Cr}$ (see table 4), and the observed-calculateddifference plots are shown in Fig. 43. The fit using model 2, containing $\mathrm{Al}_{5} \mathrm{Cr}$ instead of $\mathrm{Al}_{4} \mathrm{Cr}$, was poorer than that achieved by refining model 3. The $R_{w p}$ was higher and it did not fit the region between $2 \AA$ to $2.35 \AA$ as well (Fig. $4(b, c)$ ): intensity and width of the broad peak between $2 \AA$ and $2.05 \AA$ is not well modelled, the peaks around 2.12 $\AA$ are missing and there is an extra peak at $2.31 \AA$. Model 1 , which contained only $\mathrm{Al}$ and $\mathrm{Al}_{13} \mathrm{Cr}_{2}$, did not fit the data as well as model 3 missing several peaks and a model

\begin{tabular}{ll}
\hline Model & $R_{w p}$ \\
\hline $1-\mathrm{Al}+\mathrm{Al}_{13} \mathrm{Cr}_{2}$ & 11.13 \\
$2-\mathrm{Al}+\mathrm{Al}_{13} \mathrm{Cr}_{2}+\mathrm{Al}_{5} \mathrm{Cr}$ & 8.47 \\
$3-\mathrm{Al}+\mathrm{Al}_{13} \mathrm{Cr}_{2}+\mathrm{Al}_{4} \mathrm{Cr}$ & 6.34 \\
$4-\mathrm{Al}+\mathrm{Al}_{13} \mathrm{Cr}_{2}+\mathrm{Al}_{5} \mathrm{Cr}+\mathrm{Al}_{4} \mathrm{Cr}$ & 6.95 \\
\hline
\end{tabular}

Table 4: Quality of the fit factors $R_{w p}$ for the different model used to refine the data collected on the as-cast materials. 


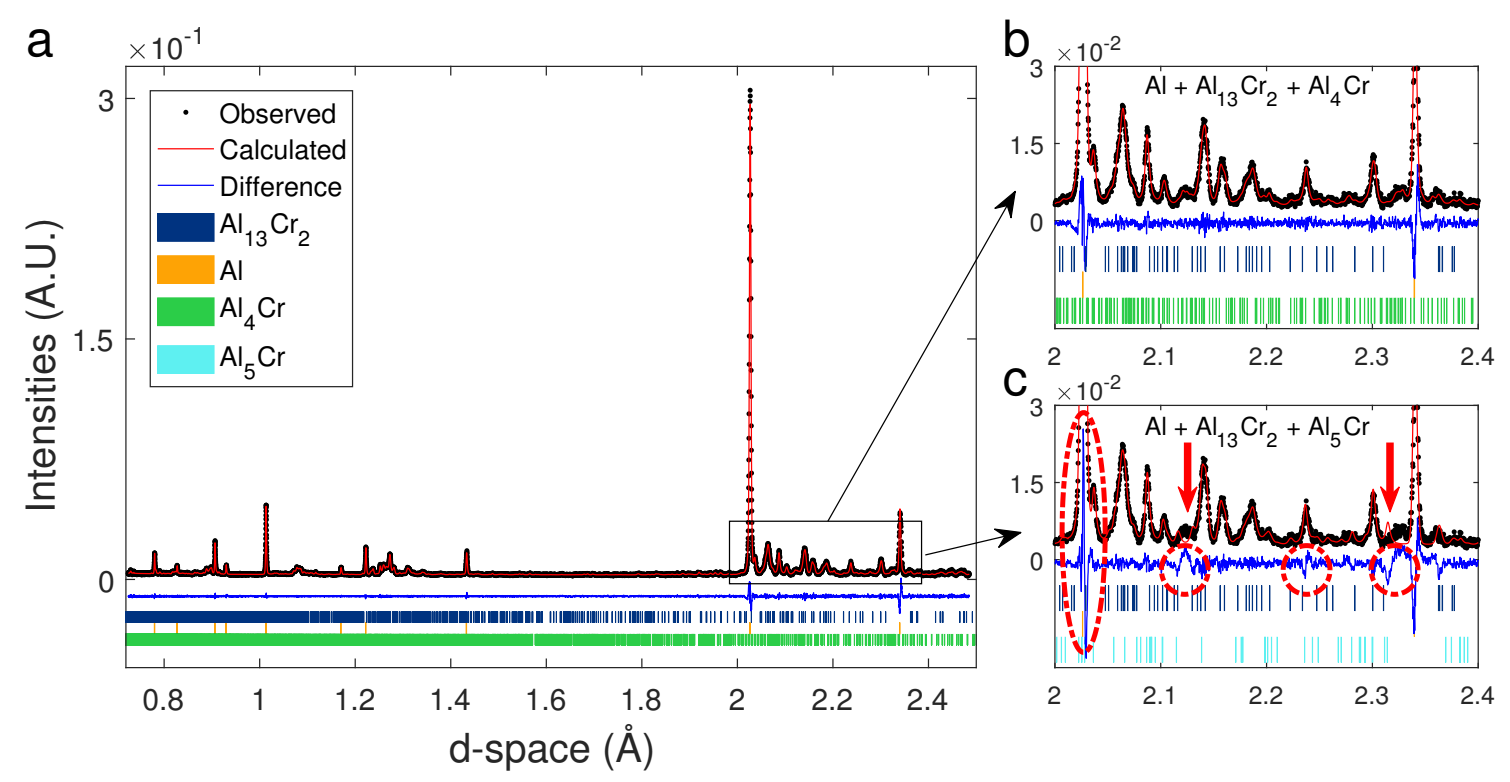

Figure 4: Observed-calculated-difference plots from refinement of the PND data collected on the ascast sample using model 3. (b) and (c) expanded region ( $2 \AA$ to $2.35 \AA$ ) showing fit of model 3 and 2 respectively. In (c) the poor fit of certain diffraction peaks is highlighted.

including all the four phases (model 4) did not improve the quality of the fit compared to model 3. Physical broadening was found to be significant and a good fit was obtained only after refining the Lorentzian profile parameters $\gamma_{1}$ and $\gamma_{2}$ for each phase. Values of the lattice parameters and microstrain for $\mathrm{Al}_{13} \mathrm{Cr}_{2}, \mathrm{Al}$ and $\mathrm{Al}_{4} \mathrm{Cr}$ are listed in table 7 .

\subsection{Annealed one day}

EPMA analysis of the material annealed for one day revealed the presence of only $\alpha$-Al and $\mathrm{Al}_{13} \mathrm{Cr}_{2}$, therefore the neutron diffraction data were fitted using a model containing only these two phases, which was found to resolve all the peaks. As for the as-cast sample, physical broadening was considerable and a good fit was obtained only after refining $\gamma_{1}$ and $\gamma_{2}$. The best Le Bail fit converged with a final $R_{w p}$ of 3.37 and the observed-calculated-difference plots are shown in Fig. 5. The values of the lattice parameters and microstrain are summarized in table 7. 


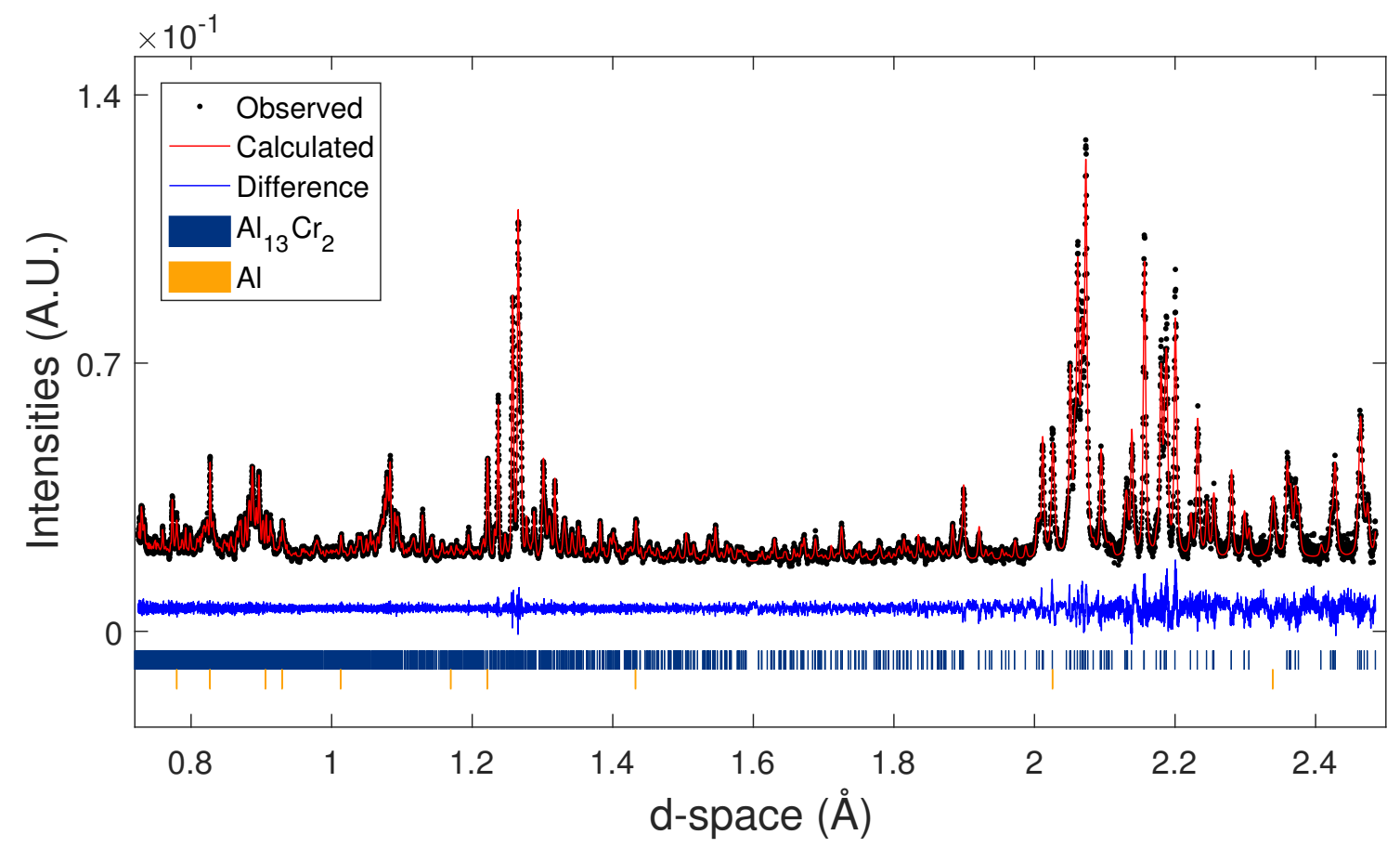

Figure 5: Observed-calculated-difference plots from refinement of the PND data collected on the sample annealed for one day at $773^{\circ} \mathrm{C}$.

\subsection{Annealed one week}

The synchrotron powder X-ray diffraction data collected on this sample was refined using a multiphase model containing $\mathrm{Al}$ and $\mathrm{Al}_{13} \mathrm{Cr}_{2}$. The fit to the data collected at $298 \mathrm{~K}$ converged with a final $R_{w p}$ of $7.35 \%$. All observed peaks could be fitted using this model, confirming the material did not contain other major phases. The observed-calculateddifference plots are shown in Fig. 6. Analysis of the data collected between $298^{\circ} \mathrm{C}$ and $773^{\circ} \mathrm{C}$ found no evidence of any phase transformations or any new phases formed. The high temperature datasets were refined using the same strategy as the data collected at $298^{\circ} \mathrm{C}$. Table 5 summarises $R_{w p}$ for each refinement. The fit quality decreased with temperature which is due to shorter data acquisition times used at higher temperatures and increasing atom vibration. The atomic positions from refinement of the $\mathrm{Al}_{13} \mathrm{Cr}_{2}$ phase are given in table 6. The refined atomic positions from the refinements at high temperatures have been included in the Supplementary Materials (CIF format). Lattice parameters and strain value are summarized in table 7. 


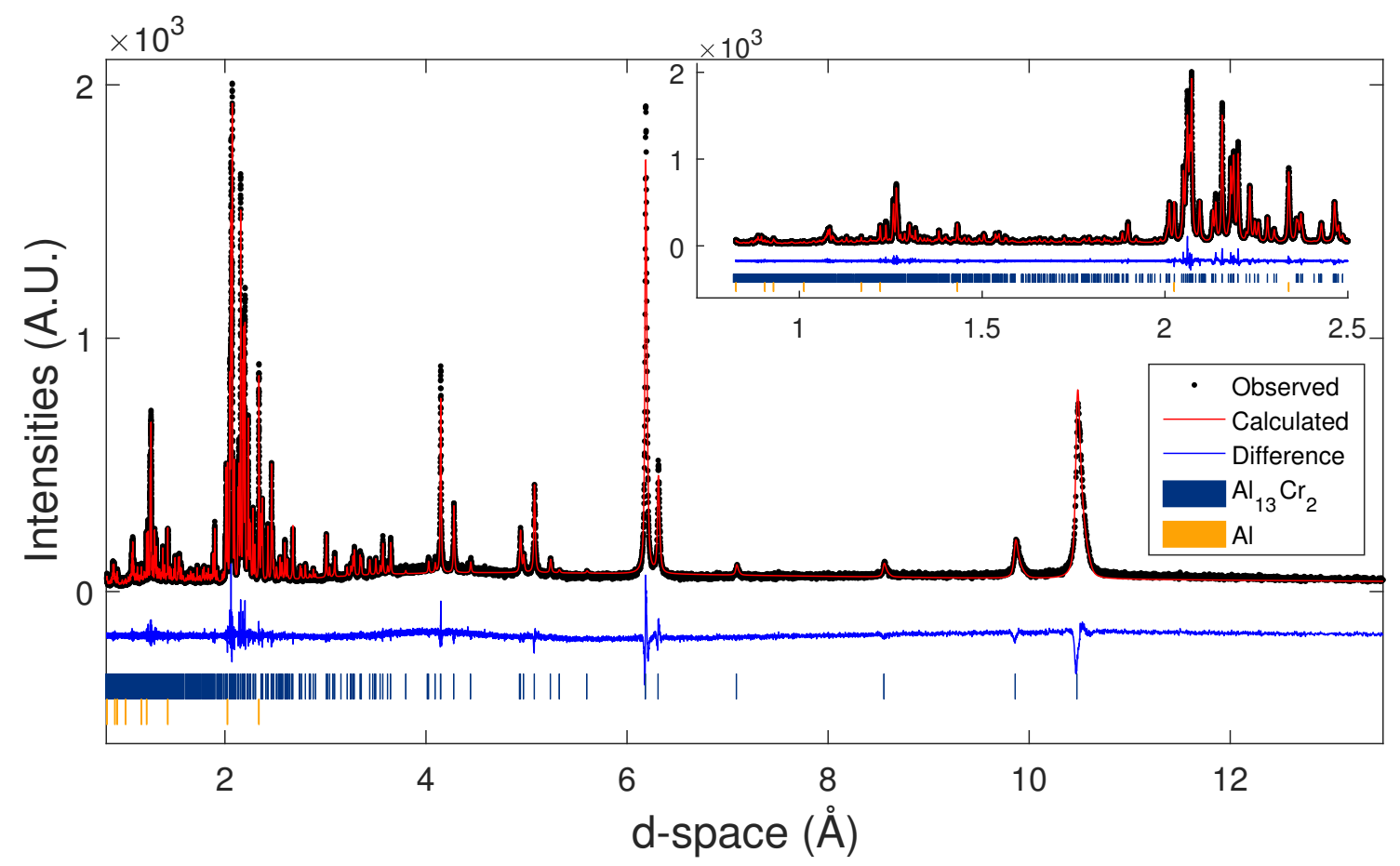

Figure 6: Observed-calculated-difference plots from refinement of the XRD data collected at $298 \mathrm{~K}$ on the sample annealed for one week. The pattern is plotted as $d$-space to compare with PND data. (Inset) Zoomed region of the diffraction pattern with the same range of the PND data shown in Figs.4 and 5

\begin{tabular}{ll}
\hline Temp (K) & $R_{w p}$ \\
\hline 298 & 7.354 \\
373 & 11.955 \\
473 & 12.457 \\
573 & 12.595 \\
673 & 12.691 \\
773 & 12.646 \\
\hline
\end{tabular}

Table 5: Quality of the fit factors $R_{w p}$ for high temperature refinements. 


\begin{tabular}{lllll}
\hline Atom & $\mathbf{x}$ & $\mathbf{y}$ & $\mathbf{z}$ & $\mathbf{B}_{\text {iso }}\left(\AA^{2}\right)$ \\
\hline Cr1 & 0.0000 & 0.0000 & 0.0000 & $0.13(7)$ \\
Cr2 & $0.2503(1)$ & 0.0000 & $0.2621(1)$ & $0.96(6)$ \\
Cr3 & $0.0852(1)$ & $0.3240(1)$ & $0.7530(1)$ & $1.04(6)$ \\
Al1 & 0.0000 & 0.5000 & 0.5000 & $0.94(5)$ \\
Al2 & $0.6150(1)$ & 0.0000 & $0.0007(3)$ & $0.83(6)$ \\
Al3 & $0.2921(1)$ & 0.0000 & $0.0679(3)$ & $0.64(6)$ \\
Al4 & $0.3750(1)$ & 0.0000 & $0.3825(3)$ & $0.34(5)$ \\
Al5 & $0.5222(1)$ & 0.0000 & $0.2871(3)$ & $1.03(6)$ \\
Al6 & $0.0818(1)$ & 0.0000 & $0.7232(3)$ & $0.63(6)$ \\
Al7 & $0.1298(1)$ & 0.0000 & $0.1470(3)$ & $0.13(4)$ \\
Al8 & $0.0902(1)$ & 0.0000 & $0.3381(3)$ & $0.76(4)$ \\
Al9 & $0.2247(1)$ & 0.0000 & $0.4609(3)$ & $0.67(4)$ \\
Al10 & $0.1807(1)$ & $0.1847(2)$ & $0.0078(2)$ & $0.97(4)$ \\
Al11 & $0.0700(1)$ & $0.3190(2)$ & $0.1495(2)$ & $0.57(4)$ \\
Al12 & $0.9650(1)$ & $0.1889(2)$ & $0.1337(2)$ & $0.67(4)$ \\
Al13 & $0.3098(1)$ & $0.3137(2)$ & $0.2403(2)$ & $0.71(4)$ \\
Al14 & $0.0467(1)$ & $0.1950(2)$ & $0.4699(2)$ & $0.14(4)$ \\
Al15 & $0.1652(1)$ & $0.3085(2)$ & $0.4757(2)$ & $0.65(3)$ \\
Al16 & $0.2062(1)$ & $0.3128(2)$ & $0.2776(2)$ & $0.57(2)$ \\
\hline
\end{tabular}

Table 6: Refined atomic positions for $\mathrm{Al}_{13} \mathrm{Cr}_{2}$ as determined by Rietveld refinement of synchrotron data collected at $298 \mathrm{~K}$ on the sample annealed for one week.

\begin{tabular}{|c|c|c|c|c|c|c|c|}
\hline Phase & & a $(\AA)$ & b $(\AA)$ & c $(\AA)$ & $\beta\left({ }^{\circ}\right)$ & $\operatorname{Vol}\left(\AA^{3}\right)$ & Strain $\epsilon(\%)$ \\
\hline \multicolumn{8}{|c|}{ As-cast PND } \\
\hline $\mathrm{Al}_{13} \mathrm{Cr}_{2}$ & & $25.3101(5)$ & $7.6081(1)$ & $10.9689(2)$ & $128.704(1)$ & $1646.83(3)$ & $0.050(2)$ \\
\hline $\mathrm{Al}_{4} \mathrm{Cr}$ & & $8.71217(8)$ & $23.9590(2)$ & $16.4169(2)$ & 119.549(1) & $2981.07(3)$ & $0.016(1)$ \\
\hline $\mathrm{Al}$ & & $4.05374(1)$ & & & & $66.61(1)$ & $0.076(1)$ \\
\hline \multicolumn{8}{|c|}{ Annealed one day PND } \\
\hline $\mathrm{Al}_{13} \mathrm{Cr}_{2}$ & & $25.2822(2)$ & $7.5948(1)$ & $10.9648(1)$ & $128.746(1)$ & $1642.08(1)$ & $0.047(2)$ \\
\hline & & $4.0512(1)$ & & & & $66.48(1)$ & $0.095(6)$ \\
\hline \multicolumn{8}{|c|}{ Annealed one week XRD } \\
\hline $\mathrm{Al}_{13} \mathrm{Cr}_{2}$ & & & & & & & \\
\hline & $298 \mathrm{~K}$ & $25.2837(1)$ & $7.59541(2)$ & $10.96636(3)$ & $128.7396(2)$ & $1642.66(1)$ & - \\
\hline & $373 \mathrm{~K}$ & $25.3151(1)$ & $7.60491(3)$ & $10.97906(6)$ & $128.7502(3)$ & 1648.42(1) & - \\
\hline & $473 \mathrm{~K}$ & $25.3556(1)$ & $7.61718(4)$ & $10.99544(7)$ & $128.7637(4)$ & $1655.88(2)$ & - \\
\hline & $573 \mathrm{~K}$ & $25.3956(1)$ & $7.62943(4)$ & $11.01177(7)$ & $128.7769(4)$ & $1663.32(2)$ & - \\
\hline & $673 \mathrm{~K}$ & $25.4375(1)$ & $7.64256(4)$ & $11.02897(7)$ & $128.7908(4)$ & $1671.20(2)$ & - \\
\hline & $773 \mathrm{~K}$ & $25.4790(1)$ & $7.65569(5)$ & $11.04601(9)$ & $128.8033(5)$ & $1679.10(2)$ & 0.00024 \\
\hline \multicolumn{8}{|c|}{ 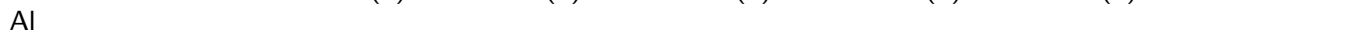 } \\
\hline & $298 \mathrm{~K}$ & $4.05020(1)$ & & & & $66.440(1)$ & 0.00014 \\
\hline & $373 \mathrm{~K}$ & $4.05727(2)$ & & & & $66.788(1)$ & - \\
\hline & $473 \mathrm{~K}$ & $4.06664(2)$ & & & & 67.252(1) & - \\
\hline & $573 \mathrm{~K}$ & $4.07613(3)$ & & & & $67.724(1)$ & - \\
\hline & $673 \mathrm{~K}$ & $4.08617(3)$ & & & & $68.226(1)$ & - \\
\hline & $773 \mathrm{~K}$ & $4.09653(4)$ & & & & $68.746(2)$ & 0.00031 \\
\hline \multicolumn{8}{|c|}{ Literature } \\
\hline $\mathrm{Al}_{13} \mathrm{Cr}_{2}$ & poper) & 25.196 & 7.574 & 10.949 & 128.72 & 1630.21 & - \\
\hline $\mathrm{Al}_{13} \mathrm{Cr}_{2}$ & hnishi) & 25.256 & 7.582 & 10.955 & 128.7 & 1637.17 & - \\
\hline
\end{tabular}

Table 7: Summary of the lattice parameters and strain values for all the phases in all the conditions obtained from the analysis of PND patterns for the as-cast and annealed for one day sample and from XRD for the sample annealed for one week. Non-reported error are negligible. 


\section{Discussion}

\subsection{Thermal stability of the phases}

The refinement of the PND patterns and the EPMA analysis both indicated that the as-cast sample contained three phases, $\alpha$-Al, $\mathrm{Al}_{13} \mathrm{Cr}_{2}$ and $\mathrm{Al}_{4} \mathrm{Cr}$, although only $\alpha$-Al and $\mathrm{Al}_{13} \mathrm{Cr}_{2}$ should form at equilibrium condition 11 . It is worth noting that several mixtures were tested in order to identify the third phase and through careful analysis of the fitted patterns, in the $d$-space region between $2 \AA$ to $2.35 \AA$, it was shown conclusively that $\mathrm{Al}_{5} \mathrm{Cr}$ was not present in the sample. The structure of $\mathrm{Al}_{4} \mathrm{Cr}$ was found to be monoclinic consistent with 17 . This phase completely dissolved after annealing the sample for one day at $773 \mathrm{~K}$ with further annealing not causing any subsequent transformation. The presence of metastable phases, for alloys with similar compositions, have been reported in previous studies of materials produced by rapid solidification methods, such as melt spinning or suction casting. With cooling rates in the order of $500 \mathrm{~K} \mathrm{~s}^{-1}$ equilibrium peritectic reactions can be suppressed or delayed $11 / 15 \mid 26+28$. The presence of the $\mathrm{Al}_{4} \mathrm{Cr}$ and not $\mathrm{Al}_{5} \mathrm{Cr}$ in the as-cast sample can be explained by considering the solidification path of a rapidly quenched liquid with nominal composition of $\mathrm{Al}_{77} \mathrm{Cr}_{23}$ (wt.\%) $\frac{11}{11}$. In this scenario $\mathrm{Al}_{4} \mathrm{Cr}$ would form first as a primary phase directly from the liquid, $\mathrm{Al}_{5} \mathrm{Cr}$ should then have formed before $\mathrm{Al}_{7} \mathrm{Cr}$, however either the peritectic reaction was suppressed, due to the high cooling rate and the narrow range of existence of the phase, or it formed but then decomposed into $\mathrm{Al}_{7} \mathrm{Cr}$ and $\mathrm{Al}_{4} \mathrm{Cr}$ by an eutectoid reaction as reported by 14 . In either case there would be no trace of $\mathrm{Al}_{5} \mathrm{Cr}$ in the material.

Non-equilibrium solidification conditions were confirmed by the level of supersaturation of $\mathrm{Cr}$ in the $\alpha$-Al phase and the estimated microstrain. Fig. 7 shows the $\mathrm{Cr}$ content measured by EPMA as a function of the annealing time along with the variation of the $\alpha$-Al lattice parameter $a$. The measured $\mathrm{Cr}$ content in the as-cast was $2.3 \mathrm{wt} \%$, which is substantially above the $0.3 \mathrm{wt} \%$ solid solubility of $\mathrm{Cr}$ in $\mathrm{Al}$ at room temperature reported in the literature ${ }^{29}$, but similar to that reported by ${ }^{27}$ for a material produced with cooling rate of $800-1000 \mathrm{~K} \mathrm{~s}^{-1}$ in an $\mathrm{Al} 2 \mathrm{wt} \% \mathrm{Cr}$ alloy. The $\mathrm{Cr}$ content decreased to $1.6 \mathrm{wt} \%$ after 1 day annealing and to $0.8 \mathrm{wt} \%$ after 1 week. The Al lattice parameter 


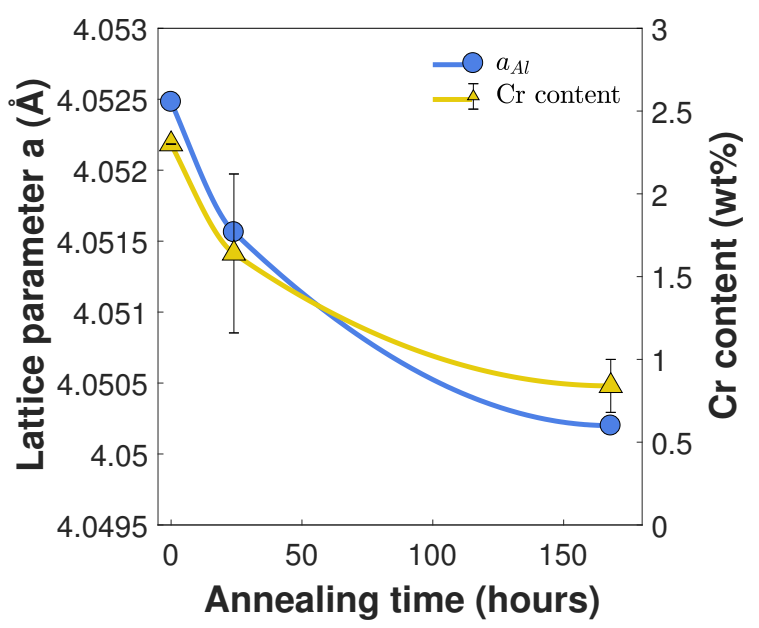

Figure 7: $\alpha$-Al $\mathrm{Cr}$ content and lattice parameter a as a function of annealing time.

$a$ decreased with time from $4.05374 \AA$ to $4.05156 \AA$ to finally $4.05020 \AA$, which closely followed the trend of decreasing $\mathrm{Cr}$ content. Decreasing $a$ values of the Al unit cell with decreasing content of $\mathrm{Cr}$ were also reported by ${ }^{13}$ for $\mathrm{Al}-\mathrm{Cr}$ sample annealed for $6 \mathrm{~h}$ at $773 \mathrm{~K}$, while ${ }^{27}$ found the opposite behaviour. The trend observed for the $\alpha$-Al lattice parameter in the present work is proposed to be related to the amount of $\mathrm{Cr}$ dissolved into the crystal structure: $\mathrm{Cr}$ atomic radius has a size of $140 \mathrm{pm}$, which is slightly larger than $\mathrm{Al}\left(125 \mathrm{pm}^{30}\right)$, and $\mathrm{Cr}$ will substitute into the $\mathrm{Al}$ crystal structure and produce an expansion of the lattice parameter also increasing the amount of microstrain as the $\mathrm{Cr}$ content increases.

All the three phases in the as-cast material contained a significant amount of microstrain, due to residual stresses induced by the high cooling rate. $\mathrm{Al}_{4} \mathrm{Cr}$ microstrain was 0.016 compared to 0.050 of $\mathrm{Al}_{13} \mathrm{Cr}_{2}$ and 0.076 of $\alpha-\mathrm{Al}$. $\mathrm{Al}_{4} \mathrm{Cr}$ had the lowest microstrain value as it formed as a primary phase directly from the liquid, while $\alpha$-Al had the largest value being the last phase forming at very high solid fraction compatibly with the proposed solidification pathway. As expected, the annealing caused the relaxation of residual stresses, which were unmeasurable after one week, although the microstrain values measured in the sample annealed for one day were 0.047 and 0.095 in the $\mathrm{Al}_{13} \mathrm{Cr}_{2}$ and $\alpha$-Al respectively almost unchanged compared to the as-cast sample. 


\section{2 $\quad \mathrm{Al}_{13} \mathrm{Cr}_{2}$ structure}

\subsubsection{Ambient conditions}

The $\mathrm{Al}_{13} \mathrm{Cr}_{2}$ was found to crystallise with monoclinic crystal structure (space group $C 2 / m$ ) consistently with previous studies ${ }^{16 \mid 17}$. The unit cell contracted slightly during the annealing and the volume was $0.26 \%$ smaller after one week as the $a$ and $b$ parameters were $0.11 \%$ and $0.18 \%$ shorter while $c$ parameter variations were overall less than $0.03 \%$. The size of the unit cell in the sample annealed for one week was very close to those reported by Cooper and Ohnishi, which were smaller by $0.76 \%$ and $0.34 \%$ respectively. It is worth noting that in the current study the measurement were carried out on bulk samples and thus the obtained volume were average over many crystallites, as opposed to the analysis of individual crystals which tends to give smaller unit cell parameters, therefore the volume differences could be ascribed to the different experimental methodologies.

\subsubsection{Thermal expansion}

Fig. 83 shows the normalized lattice parameters of the monoclinic unit cell of the $\mathrm{Al}_{13} \mathrm{Cr}_{2}$ over the temperature range $298 \mathrm{~K}$ to $773 \mathrm{~K}$ along with the $a$ parameter of the $\mathrm{Al}$, while the volume temperature variation of the unit cell are shown in Fig. 8p. All parameters exhibited a linear behaviour (linear fit $R^{2}>0.999$ ), the Al linear coefficient of thermal expansion was $24.1 \times 10^{-6} \mathrm{~K}^{-1}$, in good agreement with reported values of $24.7 \times 10^{-6} \mathrm{~K}^{-120}$ and $26.6 \times 10^{-6} \mathrm{~K}^{-1[29}$, confirming the displayed furnace temperature values were reasonable. The linear thermal expansion coefficient for the $a, b, c$ and $\beta$ parameters of the monoclinic $\mathrm{Al}_{13} \mathrm{Cr}_{2}$ were $16.3 \times 10^{-6} \mathrm{~K}^{-1}, 16.7 \times 10^{-6} \mathrm{~K}^{-1}$, $15.3 \times 10^{-6} \mathrm{~K}^{-1}$ and $1.04 \times 10^{-6} \mathrm{~K}^{-1}$ respectively. The variation of the volume with temperature of the unit cells shows that $\mathrm{Al}$ expanded at a higher rate than $\mathrm{Al}_{13} \mathrm{Cr}_{2}$. The volume thermal expansivity of Al was approximately $60 \%$ higher than that exhibited by $\mathrm{Al}_{13} \mathrm{Cr}_{2}\left(72.9 \times 10^{-6} \mathrm{~K}^{-1}\right.$ compared to $\left.45.7 \times 10^{-6} \mathrm{~K}^{-1}\right)$.

From the temperature-dependence of the monoclinic lattice constants, the four coeffi- 

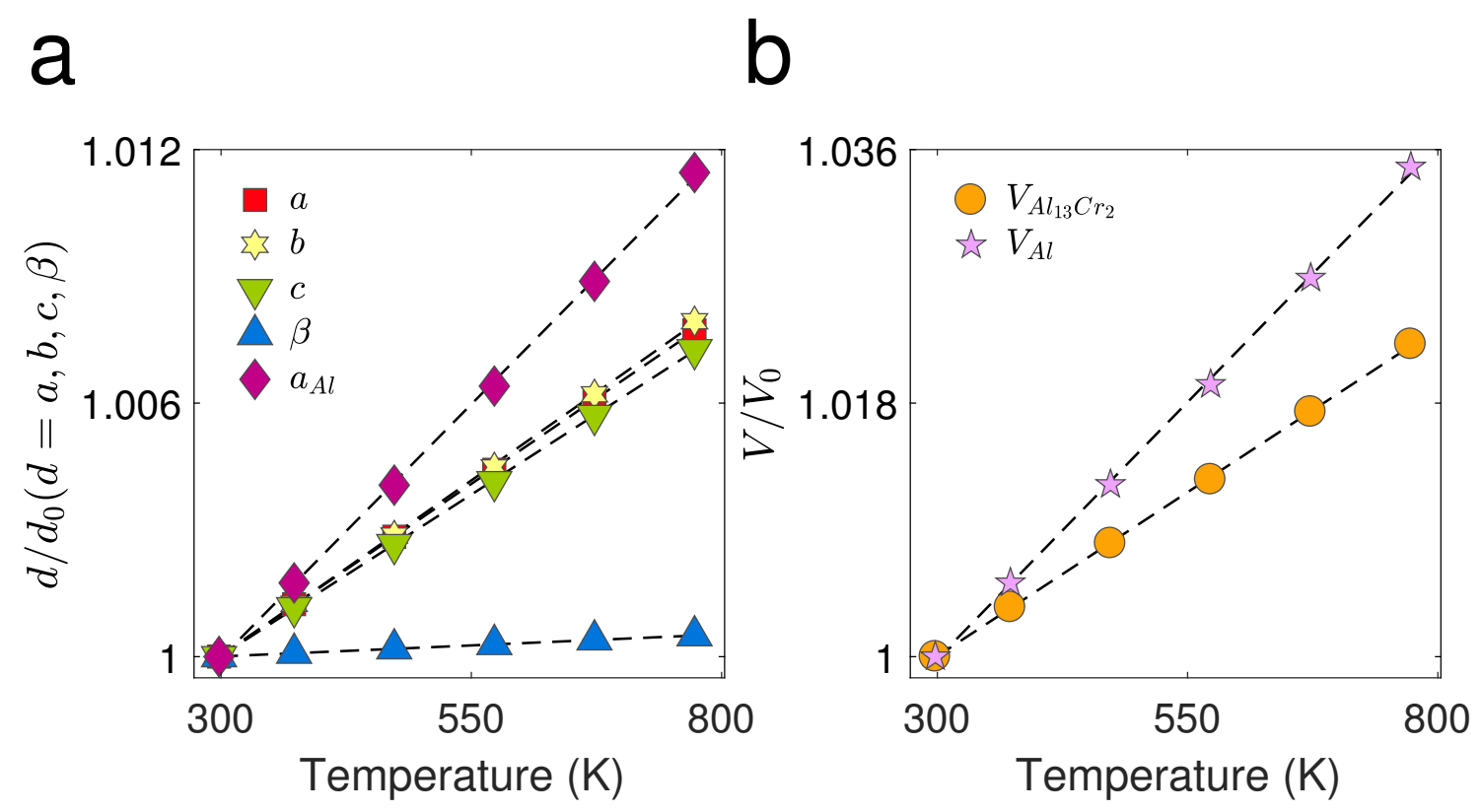

Figure 8: (a) $\mathrm{Al}$ and $\mathrm{Al}_{13} \mathrm{Cr}_{2}$ normalized lattice parameters over the temperature range $298 \mathrm{~K}$ to $773 \mathrm{~K}$ where $d$ is the lattice constant and $d_{0}$ the value of the constant at $298 \mathrm{~K}$. (b) volume variation of the $\mathrm{Al}$ and $\mathrm{Al}_{13} \mathrm{Cr}_{2}$ unit cells.

cients of the thermal expansion tensor were calculated using the expression given in 31 , and the principal axes magnitudes and directions from equations given by ${ }^{32}$. From the Neumann's principle it follows that one of the principle axes lies parallel to the crystallographic $\boldsymbol{b}$ axis, here designated as $\lambda_{22}$. The other two orthogonal axes lie in the a-c plane, and are designated $\lambda_{11}$ and $\lambda_{33}$. The thermal expansion tensor has components: $\alpha_{11}=1.43 \times 10^{-5} \mathrm{~K}^{-1}, \alpha_{22}=1.66 \times 10^{-5} \mathrm{~K}^{-1}, \alpha_{33}=1.52 \times 10^{-5} \mathrm{~K}^{-1}$ and $\alpha_{13}=-1.55 \times 10^{-6} \mathrm{~K}^{-1}$, which on diagonalization yields principal axis magnitudes of $\lambda_{11}=1.64 \times 10^{-5} \mathrm{~K}^{-1}, \lambda_{22}=1.66 \times 10^{-5} \mathrm{~K}^{-1}$ and $\lambda_{33}=1.31 \times 10^{-5} \mathrm{~K}^{-1}$. Therefore the largest principal axis lies parallel to $\boldsymbol{b}$, the second largest lies in the $\boldsymbol{a}$ - $\boldsymbol{c}$ plane at an angle of $\sim 37^{\circ}$ from $\boldsymbol{c}$ in the direction of $-\boldsymbol{a}$ and the smallest lies at $\sim 53^{\circ}$ to $\boldsymbol{c}$ in the direction of $+\boldsymbol{a}$. The orientations of the principle axis of the thermal expansion tensor are shown in Fig. 9, with the representation quadric of the thermal expansion tensor superimposed to the structure. The mean Al-Al distance at $298^{\circ} \mathrm{C}$ was $2.84 \AA$, almost identical to $2.83 \AA$ reported by Cooper ${ }^{16}$. The mean value increased linearly with temperature with an $R^{2}>0.99$, however the total increase was very small $(0.077 \%)$. Fig. 10 shows box plots of the distance distributions at each temperature compared to those calculated from the structural model described by Cooper. The $\mathrm{Al}-\mathrm{Cr}$ distances up to 

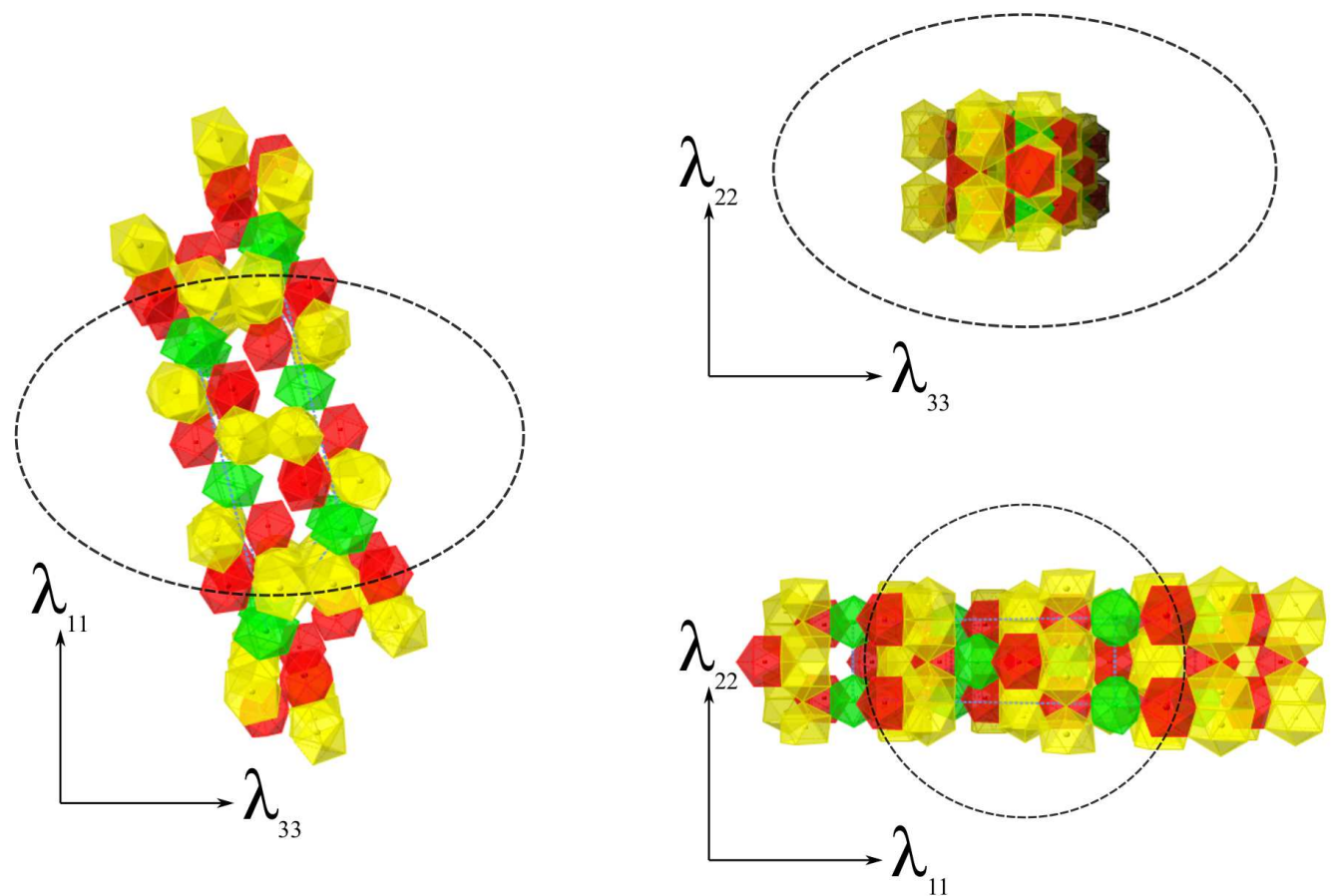

Figure 9: The orientation of the principle axes of the thermal expansion tensor at $298 \mathrm{~K}$ to the crystal structure of $\mathrm{Al}_{13} \mathrm{Cr}_{2}$. The representation quadric ellipsoid of the tensor are superimposed on the structure.

3.5 $\AA$ includes 31 bonds, 12 of which are the ones forming the icosahedra around the $\mathrm{Cr}$ atoms (bonds less than $2.59 \AA$ ). The room temperature value was $0.0107 \AA$ larger than the model published by Cooper. The distribution was highly asymmetric and broader than the $\mathrm{Al}-\mathrm{Al}$ bonds, however the mean value did expand linearly $\left(R^{2}=0.97\right)$. There is only one $\mathrm{Cr}-\mathrm{Cr}$ bond in the structure between two $\mathrm{Cr}_{3}$ atoms and part of the icosahedra around that atom. The value at room temperature was found to be larger than the model described by Cooper, $2.673 \AA$ compared to $2.666 \AA$. The distance decreased to $2.670 \AA$ at $373 \mathrm{~K}$ before increasing with further temperature increases.

Polyhedral volume calculations showed that at $298 \mathrm{~K} i \mathrm{co}_{1}$ was the largest icosahedron, while $\mathrm{iCO}_{2}$ and $\mathrm{iCO}_{3}$ were respectively $3.5 \%$ and $6.1 \%$ smaller (Fig. 11a). The volume thermal expansivity of $i \mathrm{CO}_{2}$ and $i \mathrm{CO}_{3}$ closely followed that of the $\mathrm{Al}_{13} \mathrm{Cr}_{2}$ unit cell, whereas $i \mathrm{CO}_{1}$ expanded at a greater rate as shown in Fig. 11p. In Fig. 12 the normalized variation with temperature of the interatomic distances between the central $\mathrm{Cr}$ atoms and the icosahedra vertices are plotted as a spider plot (a-c), where the isothermal lines are visually representative of the polyhedra deformations, and individually for each icosahe- 

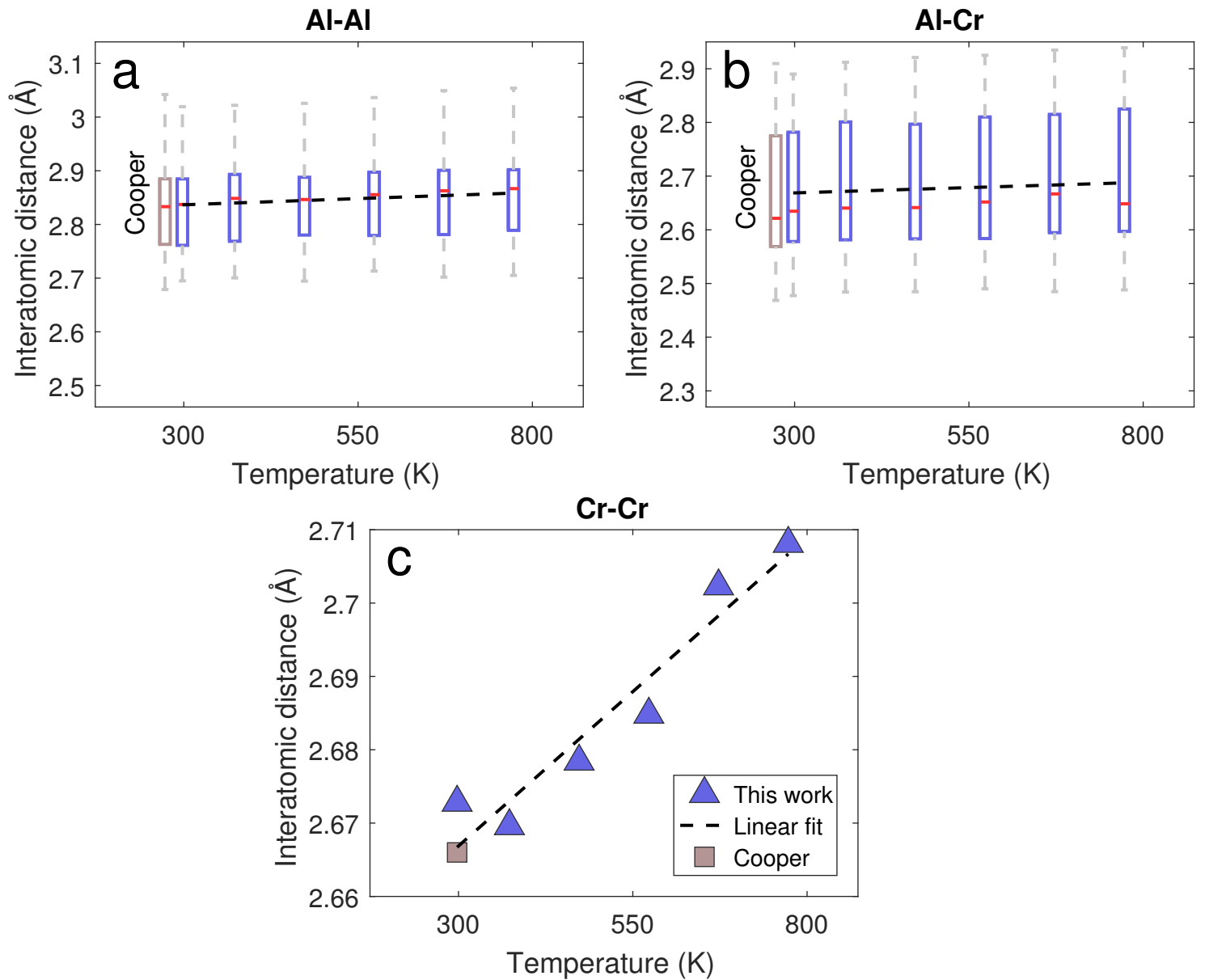

Figure 10: Box plots of the $\mathrm{Al}-\mathrm{Al}(\mathrm{a})$ and $\mathrm{Al}-\mathrm{Cr}$ (b) interatomic distances measured at increasing temperature and $\mathrm{Cr}-\mathrm{Cr}$ (c) interatomic distance. The values calculated from the model described by Cooper are reported for comparison. 

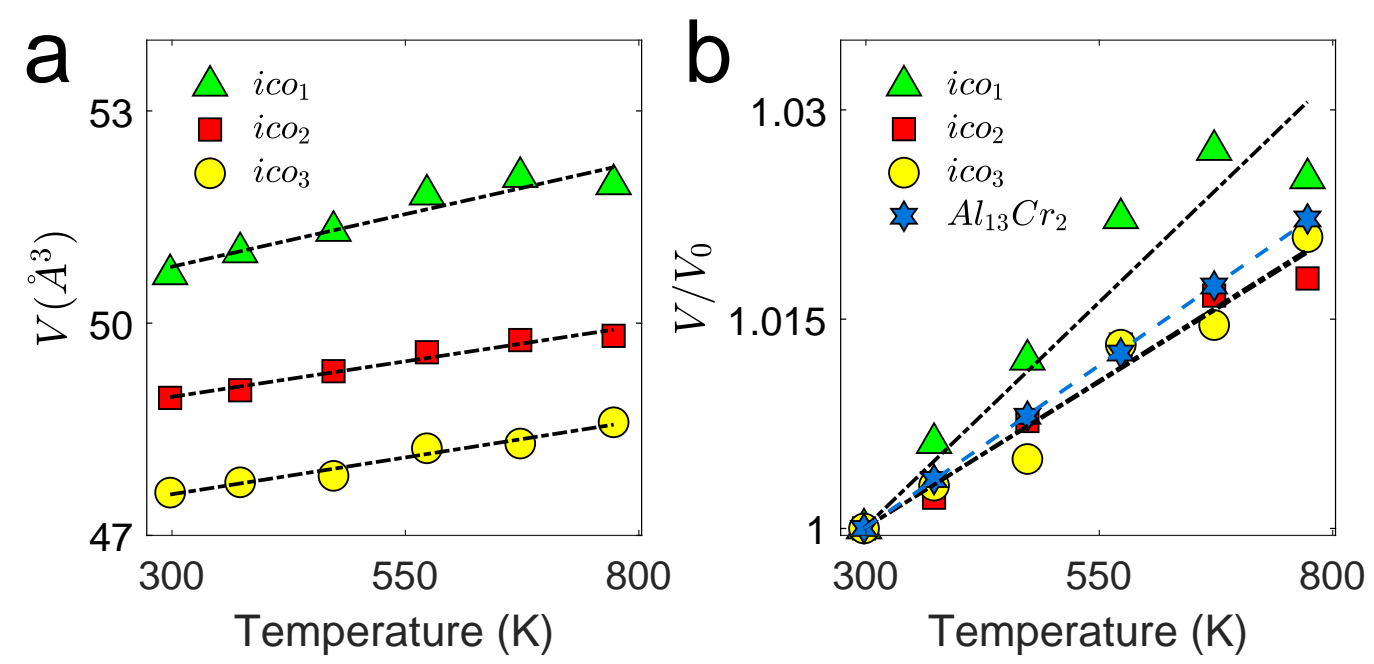

Figure 11: (a) Volume and (b) volume variation of the icosahedra around the $\mathrm{Cr}$ atoms as a function of temperature between $298 \mathrm{~K}$ to $773 \mathrm{~K}$.

dron $(d-f)$. The plots reveal that, despite the relatively uniform volume expansion, the icosahedra deformed anisotropically with more pronounced distortions as the polyhedra symmetry decreases. Furthermore, although it is difficult to identify a specific trend, some of the constraining effects of symmetry and interlinkage between icosahedra are reflected in the behaviour of the interatomic distances. For instance, $\mathrm{Al}_{3}$ and $\mathrm{Al}_{4}$ atoms are shared between $\mathrm{iCO}_{2}$ and $\mathrm{iCO}_{3}$, while the distance increases by about $1.5 \%$ between $298 \mathrm{~K}$ and $773 \mathrm{~K}$ in $i \mathrm{co}_{2}$, it slightly contracts in $i \mathrm{co}_{3} . \mathrm{Al}_{7}$ and $\mathrm{Al}_{12}$, shared between $i \mathrm{CO}_{1}$ and $i \mathrm{CO}_{2}$ and between $i \mathrm{CO}_{1}$ and $i \mathrm{CO}_{3}$ respectively, form almost collinear bonds with the two central $\mathrm{Cr}$ atoms which causes the $\mathrm{Cr}$-Al distance to be inversely related in the different icosahedra, i.e. when it increases in one it decreases in the other. $\mathrm{Al}_{10}$ is shared between ${i \mathrm{CO}_{2}}_{2}$ and $i \mathrm{CO}_{3}$ and also it is mirrored in $i \mathrm{CO}_{2}$. The symmetry in $i \mathrm{CO}_{2}$ limits its expansivity, but the bond distances in $i \mathrm{CO}_{3}$ increase quite linearly.

\section{Conclusion}

The crystal structure of the $\mathrm{Al}_{13} \mathrm{Cr}_{2}$ phase was investigated using synchrotron $\mathrm{X}$-ray and neutron powder diffraction in a set of samples: as-cast, annealed for one day and an- 


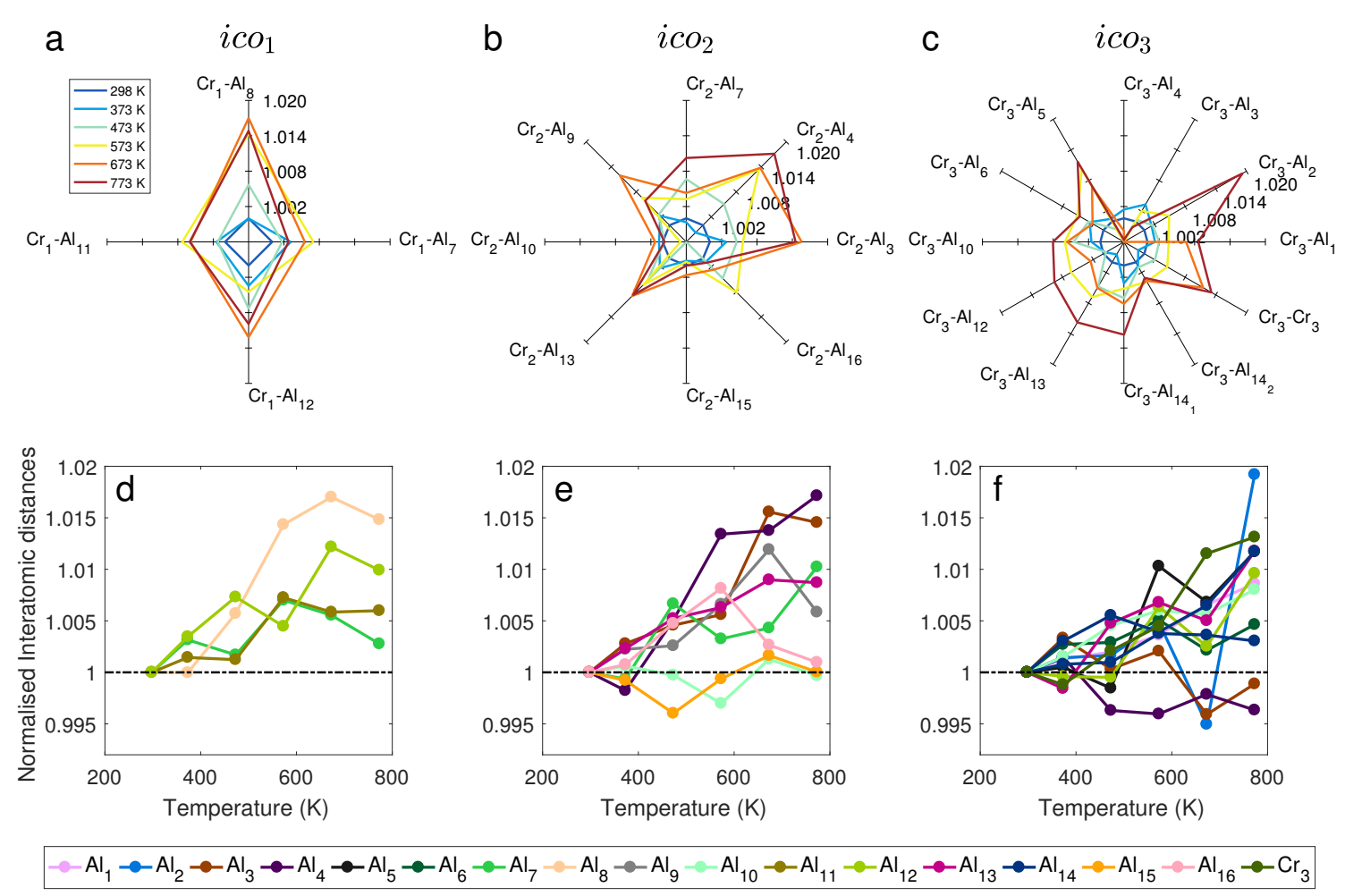

Figure 12: Normalized interatomic distance variations between the central $\mathrm{Cr}$ atoms and their nearest neighbours for $i \mathrm{co}_{1}(\mathrm{a}, \mathrm{d}), i \mathrm{co}_{2}(\mathrm{~b}, \mathrm{e})$ and $i \mathrm{co}_{3}(\mathrm{c}, \mathrm{f})$ as a function of temperature $\left(\right.$ dist $=$ dist $_{T} /$ dist $\left._{298}\right)$.

nealed for one week. The sample annealed for one week was also investigated in-situ at high temperature up to $773 \mathrm{~K}$ by synchrotron $\mathrm{X}$-ray diffraction. All samples contained impurity phases, which were identified to be $\mathrm{Al}_{4} \mathrm{Cr}$ and $\alpha-\mathrm{Al}$ in the as-cast sample and $\alpha$-Al in the annealed samples, consistent with the solidification path given in the $\mathrm{Al}-\mathrm{Cr}$ phase diagram.

Chemical analysis by EPMA determined the stoichiometry to be $\mathrm{Al}_{45} \mathrm{Cr}_{7}$, slightly Al deficient when compared to $\mathrm{Al}_{13} \mathrm{Cr}_{2}$. It is worth noting that the phase is not a line compound and three distinct stoichiometries have been reported in the literature: $\mathrm{Al}_{45} \mathrm{Cr}_{7}, \mathrm{Al}_{13} \mathrm{Cr}_{2}$ and $\mathrm{Al}_{7} \mathrm{Cr}$.

The $\mathrm{Al}_{13} \mathrm{Cr}_{2}$ was found to crystallise in the monoclinic space group $C 2 / m$, with lattice parameters $a=25.3101 \AA, b=7.6081 \AA, c=10.9689 \AA$ and $\beta=128.704^{\circ}$ at $298 \mathrm{~K}$ in the as-cast condition consistent with previous studies by Cooper $\frac{16}{16}$ and Ohnishi ${ }^{17}$. Annealing was not found to significantly affect unit cell parameters.

The analysis of the principal axes of the thermal expansion tensor revealed that the largest principal axis has a magnitude of $1.66 \times 10^{-5} \mathrm{~K}^{-1}$ and lies parallel to $\boldsymbol{b}$, the second largest lies in the $\boldsymbol{a}-\boldsymbol{c}$ plane at an angle of $\sim 37^{\circ}$ from $\boldsymbol{c}$ in the direction of $-\boldsymbol{a}$ and 
value of $1.64 \times 10^{-5} \mathrm{~K}^{-1}$ whereas the smallest lies at $\sim 53^{\circ}$ to $\boldsymbol{c}$ in the direction of $+\boldsymbol{a}$ and has a value of $1.31 \times 10^{-5} \mathrm{~K}^{-1}$.

The thermal behaviour of the icosahedra was found to be highly anisotropic and correlated to the symmetry constraint dictated by the point group symmetry of the central Cr Wyckoff site.

\section{Acknowledgements}

The authors would like to thank Chris Salter (Department of Materials, University of Oxford), for the help with the EPMA analysis, and Julia Parker and Stephen Thomson at the 111 beamline (Diamond Light Source) for the support received during the experiment. 


\section{References}

[1] Zhang, H., Wang, D. and Kuo, K. 1988, Phys. Rev. B 37(11), 6220-6225.

[2] Gerique, T., Brahmi, A., Lieblich, M. and Torralba, M. 1998, Rev. Metal. Madrid 34(4), 358-373.

[3] Grushko, B., Kowalska-Strzeciwilk, E., Przepiorzynski, B. and Surowiec, M. 2006, J. Alloys Compd. 417(1-2), 121-126.

[4] Grushko, B., Przepirorzynski, B., Pavlyuchkov, D., Mi, S., Kowalska-Strzeciwilk, E. and Surowiec, M. 2007, J. Alloys Compd. 442(1-2), 114-116.

[5] Banjongprasert, C., Hogg, S. C., Liotti, E., Kirk, C. A., Thompson, S. P., Mi, J. and Grant, P. S. 2010, Metall. Mater. Trans. A 41A(12), 3208-3215.

[6] Galano, M., Audebert, F., Cantor, B. and Stone, I. 2004, Mat. Sci. .Eng. A - Struct. 375-377, 1206-1211.

[7] Galano, M., Audebert, F., Stone, I. and Cantor, B. 2009, Acta Mat. 57, 5107-5119.

[8] Inoue, A. and Kimura, H. 1999, Nanostruct. Mater. 11(2), 221-231.

[9] Sahoo, K. and Stone, I. 2005, Phil. Mag. Lett. 85, 231-245.

[10] Inoue, A. and Kimura, H. 2000, Mater. Sci. Eng A286, 1-10.

[11] Okamoto, H. 2008, J. Phase Equilib. Diff. 29(1), 112-113.

[12] Bendersky, L., Roth, R., Ramon, J. and Shechtman, D. 1991, Metall. Trans. A 22A, 5-10.

[13] Bendersky, L., Schaefer, R., Biancaniello, F. and Shechtman, D. 1986, J Mat. Sci. 21, 1889-1896.

[14] Mahdouk, K. and Gachon, J. 2000, J. Phase Equilib. 21(2), 157-166.

[15] Murray, J. 1998, J. Phase Equilib. 19(4), 367-375.

[16] Cooper, M. 1960, Acta Cryst. 13, 257. 
[17] Ohnishi, T., Nakatani, Y. and Okabayashi, K. 1975, Bull. Univ. Osaka Prefect. 24, 183-191.

[18] He, Z., Zou, B. and Kuo, K. 2006, J. Alloys Compd. 417(1-2), L4-L8.

[19] Audier, M., Durand-Charre, M., Laclau, E. and Klein, H. 1995, J. Alloys Compd. 220, 225-230.

[20] Thompson, S., Parker, J., Potter, J., Hill, T., Birt, A., Cobb, T., Yuan, F. and Tang, C. 2009, Rev. Sci. Instrum. 80(7), 075107.

[21] Larson, A. C. and Von Dreele, R. B. 2000, General Structure Analysis System (GSAS), Los Alamos National Laboratory Report LAUR 86-748, Los Alamos National Laboratory.

[22] Toby, B. 2001, J. Appl. Cryst. 34, 210-213.

[23] Cohelo, A. 2007, TOPAS user manual, version 4.1.

[24] Snyder, R. L., Fiala, J. and Bunge, H. J. 1999, Defect and microstructure analysis by diffraction, International Union of Crystallography monographs on crystallography, Oxford University Press, Oxford; New York, chapter 7, p. 785 p.

[25] Otte, H., Montague, W. and Welch, D. 1963, J Appl. Phys. 34, 3149-3150.

[26] Esslinger, P. 1966, Z. Metallkd. 57, 12-19.

[27] Ichikawa, R. and Ohashi, T. 1971, T. Jpn. I. Met. 12, 179-183.

[28] Ichikawa, R., Ohashi, T. and Ikeda, T. 1971, T. Jpn. I. Met. 12, 280-284.

[29] Modolfo, M. 1976, Aluminium alloys: structures and properties, Butterworths.

[30] Slater, J. C. 1964, J. Chem. Phys. 41(10), 3199-3204.

[31] Schlenker, J., Gibbs, G. and Boisen, M. 1978, Acta Cryst. A34(Jan), 52-54.

[32] Knight, K. 2010, Phys. Chem. Miner. 37(8), 529-533. 